\title{
A Collaborative Approach for Engaging Students with Severe Disabilities in Physical Education
}

\author{
Michelle Grenier ${ }^{1}$, Matthew Patey ${ }^{2}$, Lauren Lieberman ${ }^{3}$, and Ali Brian ${ }^{4}$ \\ Received: $17^{\text {th }}$ September 2019; Accepted: $4^{\text {th }}$ May 2020; Published: $8^{\text {th }}$ August 2020
}

\begin{abstract}
There is research on the barriers teachers face including students with disabilities, and the extant literature is limited with regard to collaboration between general and special education. To increase the likelihood of effective collaboration, relationships among colleagues should involve on-going and sustained communication regarding students' skills. The purpose of this study was to examine the collaborative practices between general and special educators in providing access to the curriculum for students with severe disabilities in general physical education. Our primary questions included: How do general and special educators define and provide access to the general education curriculum for students with severe disabilities? How are educational goals between students with severe disabilities and their peers without disabilities developed in a general education setting? Semi-structured interviews were conducted on general and special educators $(\mathrm{N}=9)$, field note observations $(n=16)$ were conducted on one 2 nd and 4th grade physical education class that included two students with severe disabilities and their peers $(n=35)$. Collected documents included lesson plans and a teacher journal across 15 weeks of one academic semester. Data were analyzed using a thematic analysis. Three themes were identified: 1) Taking the Mystery Away, 2) Building Relationships Between Peers Through Communication Strategies and 3) It Makes Sense: Mutual Goals Between the Disciplines. Collaborative practices between special and general educators can bridge knowledge differences on content, curriculum and modes of communication that facilitate student engagement between students with severe disabilities and their peers. Recommendations for identifying communication protocols and establishing collaborative practices are provided.
\end{abstract}

Keywords: communication; inclusion; special education; thematic analysis

\section{Introduction}

As a result of legislation, advocacy, and support from international organizations, including the United Nations, the practice of including children with disabilities in general education classrooms is becoming an international movement (Pecora, Whittaker, Maluccio $\&$ Barth, 2012). For example, the right for children with disabilities to be included in general physical education (GPE) has been mandated in article 30 of the International Convention on Rights for Persons with Disability (CRPD) (United Nations, 2006). An inclusive physical education is described as an environment that provides appropriate opportunities for all 
students to engage in the curriculum (United Nations Educational, Scientific and Cultural Organization, 2015). With an increased focus on inclusion, peer interaction and curricular access, GPE teachers need knowledge on issues pertaining to advocacy, individual education plans (IEP) and working with the students' special education teams (Block \& Obrusnikova, 2007; Grenier \& Lieberman, 2018). Knowledge on how to provide resources, including services and supports within the general education setting, will enable teachers to align their content with students' specific learning needs (Grenier \& Lieberman, 2018).

However, a significant barrier to inclusion is that most general educators do not feel prepared to teach students with disabilities (Block \& Obrusnikova, 2007; Pocock \& Miyahara, 2018), nor do they understand how to develop protocols for enabling students with severe disabilities to access the general education curriculum (Ryndak, Moore, Orlando \& Delano, 2008). Pocock and Miyahara (2018) suggest the process of collaboration as a necessary step to respond to the student diversity.

Collaboration contributes to an increase in students' skill acquisition, interactions with peers and improved student outcomes (Hamilton-Jones \& Vail, 2013; Kurth, Lyon \& Shogren, 2015). Studying how collaboration becomes established in the schools to plan and provide instruction can reveal strategies that promote inclusive practices, particularly for students with severe disabilities who require significant levels of support (Cook \& Friend, 2010; Grenier \& Lieberman, 2018; Orelove, Sobsey \& Gilles, 2017).

\section{Collaborative Practices and Physical Education}

The components of collaboration include voluntary participation, equitable participation, and the sharing of resources (Hamilton-Jones \& Vail, 2013). To increase the likelihood of effective collaboration, relationships among colleagues should involve on-going and sustained communication regarding students' skills (Brinkmann \& Twiford, 2012; Waldron \& McLeskey, 2010). Professionals bring their own perspectives to the team which are then shaped by working with other team members. A shared understanding of common knowledge enables educators to incorporate their expertise into planning and instruction (Orelove et al., 2017).

There is research on the barriers teachers face including students with disabilities, however the extant literature is limited with regard to collaboration between general and special education. Teachers make decisions on inclusion based on factors including the skills and abilities of their students, their values and perspectives on inclusion, and the benefit of having students with disabilities in their classes (Timberlake, 2014). Challenges to collaboration in physical education includes teachers' attitudes, and their professional orientations (Block \& Obrusnikova, 2007; Pocock \& Miyahara, 2018; Tant \& Watelain, 2016). Many physical education teachers find it difficult to overcome their personal orientations towards students with severe disabilities, particularly if the student is not able to easily participate in learning the content (Block \& Obrusnikova, 2007; Nilsen, 2017).

A lack of preparation and confidence making the necessary curricular changes are also barriers to including students with disabilities in physical education (Block \& Obrusnikova, 2007; Bredahl, 2013; Bryan et al., 2013; Tant \& Watelain, 2016). Insufficient support, nonexistent relationships with paraprofessionals and special educators, few adaptations in the curriculum, as well as limited knowledge on students' disabilities are other primary concerns (Aydin, 2014). Compounding these issues is a lack of teachers' participation in IEP meetings (Ji \& Meaney, 2015; Samalot-Rivera, \& Lieberman, 2017). Given the limited research on collaboration between GPE and special education teachers, the purpose of this study was to examine the collaborative practices between general and special educators in providing access to the curriculum for students with severe disabilities in GPE. Specifically, we aimed to answer the questions: How do general and special educators define and provide access to 
the general education curriculum for students with severe disabilities? How are educational goals between students with severe disabilities and their peers without disabilities developed in a general education setting?

\section{Materials and Methods}

Qualitative inquiry was used to gain insight on the collaborative practices between general and special educators that facilitated the inclusion of students with severe disabilities in GPE. A selective purposeful sampling was used to conduct the research (Patton, 2015). The school, located in New England, United States, includes a diverse mix of students across a range of socio-economic levels, race and ethnicities. The elementary school served students in kindergarten through to $5^{\text {th }}$ grades and enrolled over 584 students. Its mission was to ensure a safe and successful learning community that embraced diversity as well as responding to the social, emotional, intellectual and physical needs of every child. Students' disabilities in the school ranged from severe to moderate including two students with medically unstable conditions. IEP teams met regularly to support students' learning. Information on the nature and severity of students' disabilities was shared with classroom teachers. Students with disabilities were primarily educated in the general education classroom with peers. One GPE teacher was responsible for teaching all students enrolled in the school. The primary researcher's Institutional Review Board at the University of New Hampshire granted approval for the study. Pseudonyms were used for all participants in the study. Informed consent was obtained from the observed students and interviewed participants.

\section{Participants}

The focus of this study was the collaborative teaming practices that took place for students with severe disabilities enrolled in one second grade and one fourth grade GPE class, both taught by Ms. Burns, who was the sole elementary GPE teacher in the school. She had a master's degree in education and a graduate certificate in Adapted Physical Education.

Each of Ms. Burns' classes met once a week for 50 minutes. Her GPE curriculum included a skill theme approach with additional units on dance, fitness, cooperative games, biking and snowshoeing. Ms. Burns, was a highly organized teacher with written lesson plans for each of her classes. Paraprofessionals (at a 1:1 ratio) came to the classes to support their students and frequently, related service providers, including the occupational therapist (OT), conducted their sessions in physical education.

Students with severe disabilities included one student enrolled in a second-grade class and one enrolled in a fourth-grade class. The second-grade general education class was taught by Ms. Wright, a 20-year veteran, who held master's degrees in both elementary and special education. Ms. Wright had 21 students in her class including Abby. Abby had an intellectual disability, as well as orthopedic and visual impairments. She had limited mobility in her arms and legs and used a wheelchair. A full-time paraprofessional assisted and accompanied Abby throughout the day. Abby's IEP identified necessary supports, as well as instructional accommodations and communication needs for participation in GPE (Kurth et al., 2019).

The fourth-grade class was taught by Ms. Cook, a teacher with over 26 years of experience. Her class consisted of 20 students (with and without disabilities), including one with a severe disability. Caryn had a seizure disorder, used a wheelchair for support, and required a full-time nurse. Caryn communicated primarily through facial expressions, eye contact, and pulling a bell suspended from her chair. Caryn's engagement varied widely depending on her physical and emotional state. Her IEP contained provisions for participation in GPE. Both students received occupational therapy, physical therapy and 
speech therapy services. Thus, the focus of our research was on how the IEP team collaborated with Ms. Burns to include Abby and Caryn, two students with severe disabilities, into GPE.Ms. Burns was involved in the students' IEP team that included the special education case manager, OT, physical therapist (PT) and speech therapist (ST), Caryn's nurse, and the classroom teachers. The team was responsible for the students' participation in physical education. See Table 1 for a list of participants.

Table 1. Data Collection of Participant Years of Experience

\begin{tabular}{ccc}
\hline Position & $\begin{array}{c}\text { Professional Experience } \\
\text { (Years) }\end{array}$ & Degree Earned \\
\hline $\begin{array}{c}\text { (Ms. Burns) Physical Education teacher } \\
\text { (Ms. Wright) 2nd Grade teacher }\end{array}$ & 25 & M.S.* \\
21 students including Abby & 20 & M.Ed.** \\
(Ms. Cook) 4th Grade teacher & & \\
20 students including Caryn & 28 & M.Ed.** \\
Paraprofessional & & \\
Nurse & 4 & B.A.*** \\
Occupational Therapist & 4 & R.N.**** \\
Speech Therapist & 16 & M.S.* \\
Physical Therapist & 12 & M.S.* \\
Special Educator & 16 & M.S. ${ }^{*}$ \\
& 18 & M.Ed.** \\
\hline${ }^{*}$ M.S. (Master of Science), ${ }^{* *}$ M.Ed. (Master of Education), ${ }^{* * *}$ B.A. (Bachelor of Arts), ${ }^{* * * *}$ R.N. (Registered \\
Nurse)
\end{tabular}

\section{Data Collection}

Data were collected throughout the course of one 15 week semester. Data sources were field notes, interviews with general and special education teachers, documents and a personal journal to insure a broad perspective (Creswell, 2013).

\section{Field notes}

Classroom observations conducted by the primary investigator (M.G.) included 16, 50minute GPE classes using Schatzman and Strauss' (1973) system of organizing notes, a system that utilizes three ways of organizing notes including observational, theoretical and methodological notes. Observational notes comprised the majority of note taking with eight observations conducted in the second-grade class and eight in the fourth grade GPE class. Observations focused on general and special educators' practices and how these practices supported students' engagement with peers in the curriculum. Observations also included directed interactions between Ms. Burns and her students, both with and without disabilities in the class. Some of the observed content areas included traversing on a horizonal wall, hockey, gymnastics, bowling, golf and bicycling. Parental consent was obtained for all observed students and assent was secured prior to each observation.

\section{Documents}

Lesson plans written by the GPE teacher were collected throughout the semester to assess the teacher's planning practices for students' access to the curriculum. Lessons included units of bowling, gymnastics, climbing, golf, hockey and bicycling. Ms. Burns kept a journal throughout the duration of the research to record her personal thoughts, chronicling her reflections on knowledge of students, techniques for fostering peer support, and the impact of her teaching practices on students' participation in the classroom.

\section{Semi-structured interviews}

Semi-structured interviews were conducted with direct and related service providers including Ms. Burns, the PT, the OT, the ST, the director of special education, Caryn's nurse, 
the two classroom teachers (2nd and 4th grade) and one paraprofessional upon completion of the classroom observation. All of the interviewed individuals had direct contact with the students with severe disabilities and were considered essential members of the IEP team. The purpose of the interviews was to seek participants' perceptions and experiences with collaborative practices for students with severe disabilities. To this end, participants were asked open-ended questions developed by the primary investigator and reviewed by two faculty members in higher education, one from a physical education teacher education program (PETE) (A.B.) and another from a special education program (L.L.). Both faculty members had knowledge of inclusive and collaborative practices within the general school culture. Questions included perspectives on the role of special and general educators, establishing communication protocols, peer supports and overall learning goals for the students with disabilities. Interviews were conducted by the primary investigator after the classroom observations were completed. The interviews lasted between 30-45 minutes and were conducted in a quiet setting.

\section{Data Analysis}

Data from three primary sources including field notes, documents and interviews were analyzed by the primary and secondary investigator using open coding to identify discrete concepts and patterns within the data, followed by axial coding to make connections between the codes (Corbin \& Strauss, 1990). Each of the codes were identified by pasting excerpts from the transcripts within an excel file and flagging each with the identified code with a reference to the transcript page and line number (Richards \& Hempshill, 2018). The researchers reviewed the primary research question to group similar codes, and then finalize the themes to capture the qualitative richness of the phenomenon under investigation (Boyatzis, 1998; Creswell, 2013). Those that operated within the same contextual level were grouped together and combined, forming the themes presented in the results. For example, as a primary category, communication evolved from codes of observed student interactions and a communicative dictionary. Interpretive rigor and credibility of data were addressed by having all participants verify their transcripts and interpretations of themes by email or personal contact. Member checking was conducted by the primary investigator with the teachers, asking them to provide feedback and any clarifications or elaborations they wanted to make on the transcribed interviews (Zitomer \& Goodwin, 2014). A "critical friend" from an adapted physical education program in higher education independently reviewed the data and negotiated the themes with the primary investigator (Foulger, 2010). This practice held the investigator accountable and provided an unbiased lens. Finally, a negative case analysis of text that conflicted with the themes were conducted by the primary investigator and the "critical friend." Refer to Table 2 for examples of codes and categories.

\section{Investigator Role and Positionality}

Reflexivity and transparency are indicators for interrogating bias in the data collection (Galdas, 2017). Positionality of the researcher's professional and personal background, given her long-term relationship with Ms. Burns, and her experience as a physical education teacher lend to investigator credibility (Whittemore, Chase \& Mandle, 2001). Sharing her experiences of teaching with Ms. Burns allowed for a candid exchange in which participants openly discussed their teaching experiences and personal views. Positioning herself as an investigator interested in collaborative inclusive practices for the purposes of advancing inclusive practices was essential for establishing communication and offering an opportunity for interviewees to openly discuss their teaching practices and educational perspectives. 
Table 2. Examples of Codes and Categories

\begin{tabular}{|c|c|c|c|}
\hline Data Source & Example of Codes & Example of Categories & Theme \\
\hline Interview & Student benefits & Student relationships & \\
\hline Interview & Thoughts on inclusion & Inclusive pedagogy & Taking the Mystery \\
\hline Personal Journal & $\begin{array}{c}\text { Building a relationship with an } \\
\text { OT, early in career }\end{array}$ & Healthy relationships & Away Among Peers \\
\hline Interview & Attending PT sessions & $\begin{array}{l}\text { Collaboration with } \\
\text { other professionals }\end{array}$ & \multirow{3}{*}{$\begin{array}{c}\text { Bridging } \\
\text { Communication } \\
\text { and Building } \\
\text { Relationships }\end{array}$} \\
\hline Personal Journal & $\begin{array}{l}\text { Teaching students how to } \\
\text { communicate }\end{array}$ & $\begin{array}{l}\text { Communication is } \\
\text { needed for student } \\
\text { interaction }\end{array}$ & \\
\hline $\begin{array}{c}\text { Field } \\
\text { notes/lesson } \\
\text { plans }\end{array}$ & $\begin{array}{l}\text { Body gestures as a form } \\
\text { communication }\end{array}$ & $\begin{array}{l}\text { Non-verbal } \\
\text { communication }\end{array}$ & \\
\hline Interview & $\begin{array}{l}\text { Passing on knowledge about } \\
\text { students to others }\end{array}$ & Sharing information & \multirow{3}{*}{$\begin{array}{c}\text { It makes Sense: } \\
\text { Mutual Goals } \\
\text { Between the } \\
\text { Disciplines }\end{array}$} \\
\hline Interview & $\begin{array}{c}\text { Conferencing with other } \\
\text { educators }\end{array}$ & $\begin{array}{l}\text { Learning from each } \\
\text { other }\end{array}$ & \\
\hline Personal Journal & $\begin{array}{l}\text { Sharing lessons so OT and PT } \\
\text { can preview lessons to students }\end{array}$ & Being a team & \\
\hline
\end{tabular}

\section{Results}

Three themes emerged from the data. The first theme, Taking the Mystery Away, described Ms. Burns collaborations with the IEP team as a way to further her understanding of her students' needs. The second theme, Building Relationships Between Peers Through Communication Strategies, described the collaborative steps and educational practices that contributed to students' meaningful participation in GPE. The final theme, It makes Sense: Mutual Goals Between the Disciplines, described the development of learning goals that aligned the general education curriculum with those of the students with severe disabilities.

\section{Taking the Mystery Away}

Ms. Burns believed in the value of an inclusive placement, however her limited knowledge on practices that bridged learning differences between her students with severe disabilities and their peers prompted her to seek information from the IEP team. She was particularly troubled by the lack of interaction between her students with severe disabilities and their peers. The term "floating island," was a personal journal entry used to illustrate the social isolation from peers her students with disabilities experienced despite their physical presence in the classroom (Personal Journal). Identifying and recognizing this need prompted her to reach out to the IEP team:

I knew that there was something missing in my teachings, I just didn't know how big it was until I started this process. By partnering with the professionals that work with my students I would be able to learn the goals they have for their students and hopefully adapt those goals to make the GPE class more accessible (Personal Journal).

Working with the team was essential for Ms. Burns to further her knowledge on the needs of the students. This required an on-going dialogue between general and special educators so that each member of the team was aware of the content that was being taught and was able to support the instruction that occurred from one another's view. According to the PT:

Collaboration takes the mystery away. As an educator, you need to ask what are the requisite skills from a special education perspective? What are the skills 
you would want in a PE [physical education] teacher in order to facilitate meaningful inclusive practices?

The OT also shared her perspective:

I'm not sure that every school has weekly consults for these students but going to that meeting you are listening and talking. That makes the difference.

Without coming to those meetings and having the discussions that we had, it would not have worked as well.

Team meetings focused on students' needs, progress toward IEP goals, the content and how to include the students in the class which was a learning process for Ms. Burns. As noted by the ST:

These are students who have very significant disabilities that require really specific training and education, and I think it took Ms. Burns a while to find this out... To get down to that level of thinking takes a while. It's not intuitive.

Including the students by promoting meaningful peer interactions motivated Ms. Burns to learn about her students' specific communication needs and skills. She began attending PT and OT sessions to help her understand the students' skills, communication patterns and IEP goals. Attending the sessions provided her with specific modeling practices she could incorporate into her lessons.

In analyzing Abby's IEP, I was able to see that her strengths included intermittent eye contact and right-hand dominance. She is motivated by the colors yellow and orange, will turn her head to look at familiar voice or music, and sway back and forth if interested. Her needs include mobility (wheelchair), 1-on-1 adult for safety and care, and her understanding of language is limited. Speech, occupational and physical therapy goals include turning her head toward the speaker and reaching and touching objects when given verbal cues and elbow prompts (Personal Journal).

Ms. Burns interactions with the team reinforced a sense of shared responsibility:

Seeing them in a different environment and attending their therapy sessions really helped a lot. But also, I really felt that me being part of the team meetings was important; to let them know I'm invested in who the student is and their success (Personal Journal).

Planning for and implementing access to the general education curriculum required teachers discuss and respect each other's perspective.

Once I started this process the learning curve was huge. What really helped my development was the collaborative approach to teaching. Another thing I didn't realize is how this collaborative approach would go beyond the three specialists [OT, PT and ST] to our working together to have a better understanding of my students (Personal Journal).

Team members also recognized her commitment to the process: "Ms. Burns truly has the belief that she has an important job about physical education and she's very passionate about it. She is involved and talks to the team" (ST). The relationships also contributed to Ms. Burns sense of purpose:

What expertise do I have to contribute to the equation? As a GPE teacher I have a lot of experience in the PE [physical education] environment; motivating students, breaking down materials and teaching in a way that motivates students to learn and be successful interacting with each in the gymnasium (Personal Journal) 
Both these informal and formal approaches to Ms. Burns professional development foregrounds the need for teachers' to take an active interest in the learning needs of their students with disabilities.

\section{Building Relationships Between Peers Through Communication Strategies}

Meaningful inclusion and a sense of belonging within an inclusive setting requires communication between peers (Wilhelmsen \& Sorensen, 2017). Understanding the students non-verbal modes of communication was necessary for students to communicate with each other. Non-verbal communicative behaviors are the ways an individual student initiates and responds to conversations. This can include eye contact, sounds, smiles, body movement and/or reaching and touching (Calculator, 2009). Learning to interpret students' gestural behaviors by attending the team meetings and therapy sessions was essential for Ms. Burns' understanding of the students' communication skills.

I thought if I could get those answers then I could teach their peers how to "read" their friends with disabilities' non-verbal and verbal cues. I kept asking myself, what constitutes communicative behavior and what do they perceive to be the meaning of each message? (Personal Journal).

Creating a communication list that identified Abby and Caryn's gestural behaviors was one of Ms. Burns' first tasks. For example, Abby's rocking motion from side-to-side meant she was engaged. When she lowered her head, she was tired and disinterested. See Table 3 for examples of the communication list.

Table 3. Examples of Abby and Caryn's Communicative Dictionary/Language

\begin{tabular}{|c|c|}
\hline Abby's Dictionary & Caryn's Dictionary \\
\hline $\begin{array}{l}\text { Abby's field of vision is best on the right diagonal side \& } \\
\text { Abby is right-handed. } \\
\text { Turning to look at you means interested. } \\
\text { Reach to touch means want something, saying hi, } \\
\text { interested. } \\
\text { Swaying back and forth means engaged, interested. } \\
\text { Smile means recognizing face, voice or music. } \\
\text { Head down, turn away means tired, done. } \\
\text { Making noise means interested, or not feeling well. } \\
\text { Bubbling means working hard, concentrating. }\end{array}$ & $\begin{array}{l}\text { Caryn is right-handed \& diagonal field of vision is } \\
\text { the best. } \\
\text { Turning to look at you means interested. } \\
\text { Reach to touch means want, interested. } \\
\text { Smiles, laughs means happy. } \\
\text { Flips her bell means attention, happy. } \\
\text { Moves legs and flaps arms means interested. } \\
\text { Grimacing means does not like. } \\
\text { Vocalizations means "Woo, Woo" - something not } \\
\text { feeling right. } \\
\text { Hands together means content. } \\
\text { Retraction of arms means not wanting something to } \\
\text { continue. } \\
\text { Says "mmm" means more, continue. }\end{array}$ \\
\hline
\end{tabular}

Ms. Burns relationship with the IEP team members was a crucial factor in meeting the learning needs of the students. According to the ST:

She would come to the team meetings and ask, "what does this all mean?" or "Is Caryn communicating that she wants something or doesn't want something?” Although Ms. Burns had worked with Caryn for years, however in not talking to the team members she hadn't picked up on how students with these significant disabilities communicate. Her initiative to come to the team and finding those things out helped her develop the dictionary. She initially implemented communication in a way that had not worked. Talking this over with the team gave her ideas on how they communicate. She made it work!

Her evolving insight on the students' communication modes while creating opportunities for them to communicate with their peers informed the way she planned her lessons to consider student interactions. According to Ms. Burns, "have students start off 
with just saying hello. Whether it's you and the student, or the peers and the student, understand that you've made a connection" (Interview). She embedded verbal scripts between students into her lesson planning which she shared with other team members (lesson plans).

Ms. Burns identified peers who would engage with the students over a number of classes so they could learn the communication protocol. According to Ms. Burns:

Two peers would be partners for several classes which would give the peers a chance to bond, learn the routine and be predictable. I would choose peer partners considering a variety of attributes to make this a meaningful and successful relationship. (Interview).

Successes within the classroom increased her sense of purpose:

The other day I was talking with the speech therapist about Abby and about her communicative behaviors. She and I had met previously to discuss how Abby could initiate a communicative behavior when she was actively turning her head from side to side. It was awesome - Abby had been working with the same peer the last two classes. Abby's peer was able to see her try to communicate when she initiated an interaction. Their interactions have been sometimes right on, sometimes flat, and this time, amazing! (Interview).

This passage elaborates on the nature of Ms. Burns' perceptions of inclusion as a result of her work with the IEP team, particularly the extent to which these experiences cultivated a broader understanding of inclusion.

\section{It Makes Sense: Mutual Goals Between the Disciplines}

The success Ms. Burns witnessed developing communication between students furthered her desire to embed learning goals for both students with and without disabilities in her lessons. She made detailed lesson plans that specified the learning protocols for both students with and without disabilities, checking in with the IEP team to insure she was on target:

We [IEP team] reviewed the lesson plans I created with the team to see if the lesson was developed in a way the student would be able to access the content and learn the skills. I asked if I was reinforcing their OT, PT and speech goals in a way that the student would be familiar with, and then making that bridge for the student to be able to access my lesson and be successful with some predictability. The team was very supportive of the goals I had for our students by providing feedback into my lessons to help for student success (Ms. Burns, interview).

The effectiveness of her lessons were noted by Caryn's nurse who made every effort to ensure Caryn attended her weekly GPE class:

She knows what to expect, she knows it's going to be fun, she's moving, and she loves to move. I think if its consistent and she's feeling well, it is good...This is the best part of her day... I think it has changed her level of engagement

Coherent and coordinated educational efforts were required for Caryn and Abby to receive specialized instruction in the gymnasium. Moreover, on-going discussions with the team helped the specialist appreciate physical education as a site for providing their services. According to the PT:

Instead of taking them out and doing something away from peers we would include them into the gymnasium and work with them in the gymnasium. We had to ask ourselves, how do we fit in therapy time and still be a group and participate in physical education? Ms. Burns is really getting involved and 
saying 'let's modify that activity so that the students can participate with the activity' made that possible (Interview).

Mutual goals between the educators were reinforced across both settings.

When I write my PT goals, I'm writing one right now about going from kindergarten to first grade and her issue is motor coordination and visual motor skills. Well, I know that they are going to be doing soccer. So that's the skill I'm going to be working on-dribbling, soccer, and ball control. We are going to work on achieving those goals for her coordination. It makes sense (PT).

Ms. Burns' lesson plans included scripts embedded in the activities (document), which she disseminated to paraprofessionals prior to the start of class. As soon as students entered the class, she sat them down, outlining the goals for the day. During this time, she provided specific examples that prepared the students for engaging with their classmates with disabilities. This trickle-down effect, from the IEP team members to the students in the classroom, resulted in shared learning goals consistent with Ms. Burns' practices that sought to support student engagement with peers through an expansive curriculum that addressed a range of abilities.

Team support enabled the teachers to increase their understanding of how to create learning environments where the needs of their students were met (Pocock \& Miyahara, 2018). Decisions about what content would be accessed by students were guided by three factors-the needs of individual students, the content being taught, and the necessary curricular adjustments for student learning.

\section{Discussion}

This study examined how multiple educational personnel in an elementary school provided students with severe disabilities access to the general education curriculum through their collaborative practices. The results align with research that supports a collaborative approach between general and special education teachers to enhance student learning for students with disabilities (Block \& Obrusnikova, 2007; Browder et al., 2006; McGrath, Crawford \& O'Sullivan, 2019; Pocock \& Miyahara, 2008; Orelove et al., 2017; Wilhelmsen \& Sorensen, 2017). For inclusion to be effective, teachers must engage in collaborative change processes that yield new norms and practices throughout the school culture (Fullan, 2001).

To answer to our first research question on how general and special educators define and provide access to the general education curriculum for students with severe disabilities, the collaborative team considered how the curriculum could be accessed by the students through a shared understanding of the students' communication modes and learning skills (Cook \& Friend, 2010; Orelove et al., 2017). The collaboration between IEP team members allowed all participants to have a voice, engage in dialogue, and actively participate to identify the shared goals between general and special educators (Browder et al., 2006).

IEP members supported each other in their efforts to promote peer communication and access to the curriculum through on-going discussions and valuing each other's contributions (Carter, Prater, Jackson \& Marchant, 2009; Cook \& Friend, 2010; Dymond, Renzaglia, Gilson \& Slagor, 2007). Through regularly scheduled meetings, general and special educators were able to identify the environmental supports that bridged communication differences. Communication protocols between students were strategically embedded in Ms. Burns' lesson plans to ensure that students with disabilities engaged with their peers in developing and promoting positive relationships (Causton \& Tracy-Bronson, 2015; Downing, Hanreddy \& Peckham-Hardin, 2015; Olson et al., 2016). 
The findings are consistent with the research on collaboration and the impact on teacher practices. Ms. Burns' minimal experience teaching students with severe disabilities and her need to gain knowledge of her students' educational needs was a motivating factor for collaborating with the IEP team (Brinkmann \& Twiford, 2012; Pocock \& Miyahara, 2018). By acknowledging her limitations, Ms. Burns devoted time and energy to the process of change that involved considering how her curricular goals could be accessed by her students with severe disabilities. She accomplished this by attending IEP meetings, observing therapy sessions and sharing her lessons (Orelove et al., 2017). She took responsibility to gather information on the student's disability (Pocock \& Miyahara, 2018). Within her daily lessons, Ms. Burns deliberately identified structured interactions, including students greeting each other through eye contact and touch which she shared with the IEP team.

With regard to the second question on how educational goals between students with severe disabilities and their peers without disabilities are developed, successful engagement with the curriculum was dependent on the teams' ability to identify their students' skills and necessary supports (Ji \& Meaney, 2015; Olson et al., 2016; Waldron \& McLeskey, 2010). The collaborative efforts between the general and special educators contributed to students' involvement in the curriculum (Block \& Obrusnikova, 2007; Finnerty et al., 2019; Florian, 2014; Wilhelmsen \& Sorensen, 2017). Team members articulated a commitment to working together to reinforce learning goals in the GPE setting (Browder et al., 2006; Grenier \& Lieberman, 2018). As a result, Abby and Caryn were able to receive instruction and supports to meaningfully access social and academic learning opportunities (Ryndak et al., 20082009). Learning goals within the GPE setting accommodated both occupational and physical therapy goals (Finnerty et al., 2019). Meeting sessions were a priority for planning student access to the curriculum. Collaboration meant not only working in teams but listening and communicating with others in an authentic manner. See Figure 1 for a visual of the impact of collaborative teaming on student access to the curriculum.

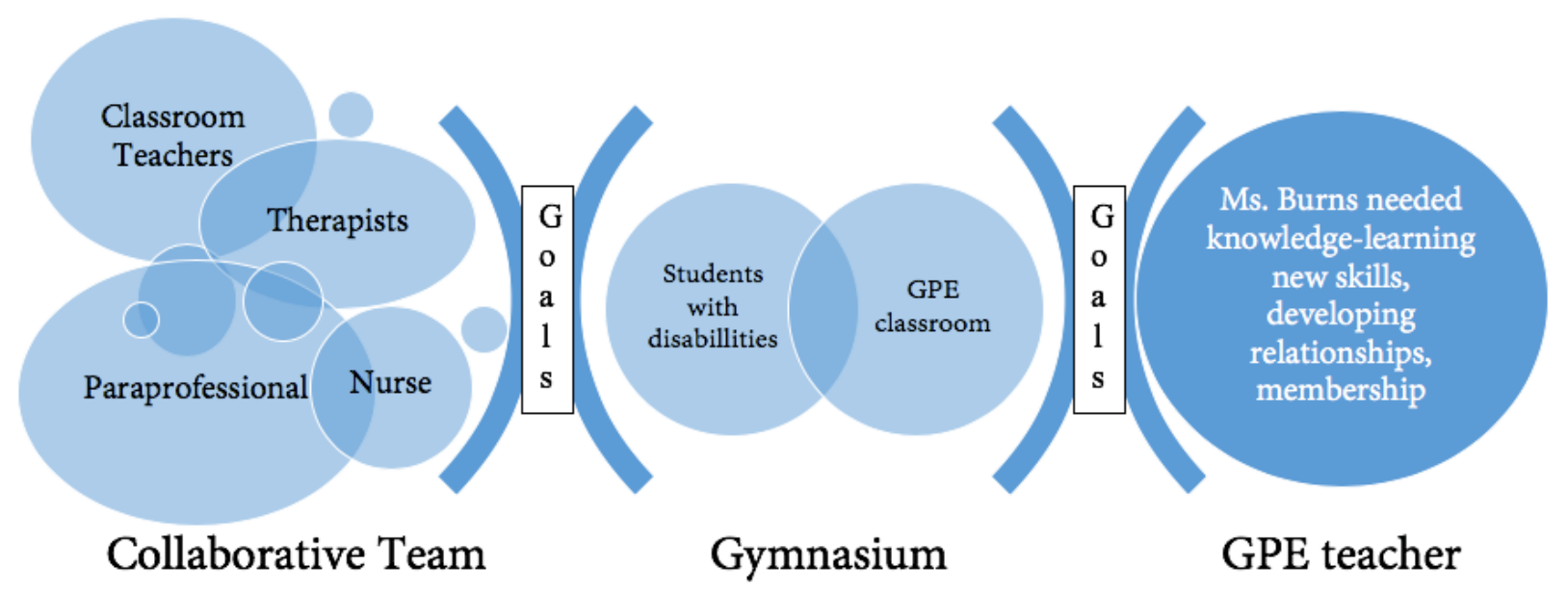

Figure 1. Impact of Collaborative Teaming on access

The case was purposefully selected to investigate this particular context and the key stakeholders involved in the school given that, there is a limit to generalizations drawn from the findings (Lincoln \& Guba, 1985). This study's small sample was limited to three general education teachers, seven special educators, and two students with severe disabilities. Multiple site comparisons could illuminate variations in collaborative practices. Another limitation was the duration of the research. Prolonged time in the setting would have generated more data on an increased understanding of the students' progress. 


\section{Perspectives}

This study illustrates the need for teachers to adopt collaborative practices to support students with disabilities in GPE. Within the bounds of this particular school, both general and special education teachers demonstrated a shared valued system of collaboration that supported students' access to the curriculum (An \& Meaney, 2015; Pocock \& Miyahara, 2018). In particular, the physical education teachers desire to have her students communicate with each other was a driving force for her collaborations with the IEP team. Consistent with the finding of An and Meaney (2015), Block and Obrusnikova, (2007) and Wilhelmsen and Sorensen, (2017) the research demonstrates the importance of working collaboratively to provide support in GPE including peer mentors, related service providers and paraprofessionals. In collaboration with the IEP team, the physical education teacher's development of a communication dictionary enabled her to embed strategic peer interactions in her lessons (Klavina, \& Rodionova, 2015; Pocock \& Miyahara, 2018; Wilhelmsen \& Sorensen, 2017). Recommendation includes the need for teacher preparation programs to plan directed practices within collaborative teams in student teaching and internship placements (Ammah \& Hodge, 2005-2006; Block \& Obrusnikova, 2007; Florian, 2014; Grenier \& Lieberman, 2018).

\section{Author affiliations:}

1 Department of Kinesiology, University of New Hampshire Durham, New Hampshire, michelle.grenier@unh.edu

2 Department of Movement Arts, Health Promotion and Leisure Studies, Bridgewater State University, Bridgewater, Massachusetts; mpatey@bridgew.edu

3 Department of Kinesiology, Sport Studies and Physical Education, The State University of New York at Brockport, Brockport, NY; llieberman@brockport.eduDepartment of Physical Education, University of

4 South Carolina, Columbia, South Carolina; abrian@sc.edu

* Correspondence: michelle.grenier@unh.edu; Tel.: (603) 862-1835

Author Contributions: Conceptualization, M.G. \& L.L.; Methodology, M.G., L.L. \& A.B.; Formal Analysis, M.G. \& M.P.; Writing-Original Draft Preparation, M.G.; Writing-Review \& Editing, M.G., L.L., A.B. \& M.P.

Funding: This research received no external funding.

Conflicts of Interest: The authors declare no conflict of interest.

\section{References}

Ammah, J. O., \& Hodge, S. (2005-2006). Secondary physical education teachers' beliefs and practices in teaching students with severe disabilities: A descriptive analysis. The High School Journal, 89(2), 40-54. https://doi.org/10.1353/hsj.2005.0019

An, J., \& Meaney, K. S. (2015). Inclusion practices in elementary physical education: A social-cognitive perspective. International Journal of Disability, Development and Education, 62(2), 143-157. https://doi.org/10.1080/1034912X.2014.998176

Aydin, M. (2014). Assessing knowledge levels of secondary school physical education and sports teachers about inclusive education. Educational Research and Reviews, 9(21), 1115-1124. https://doi.org/10.5897/ERR2014.1902

Block, M. \& Obrusnikova, I. (2007). Inclusion in physical education: A review of the literature from 1995-2005. Adapted Physical Activity Quarterly, 24, 103-124. https://doi.org/10.1123/apaq.24.2.103

Boyatzis, R. (1998). Transforming qualitative information: Thematic analysis and code development. Thousand Oaks, CA: Sage.

Bredahl, A. (2013). Sitting and watching others being active: The experienced difficulties in PE when having a disability. Adapted Physical Activity Quarterly, 3o(1), 40-58. https://doi.org/10.1123/apaq.30.1.40

Brinkmann, J., \& Twiford, T. (2012). Voices from the field: Skill sets needed for effective collaboration and co-teaching. International Journal of Educational Leadership Preparation, 7(3), 1-13. https://eric.ed.gov/?id=EJ997467 
Browder, D., Spooner, F., Wakeman, S., Trela, K., \& Baker, J. (2006). Aligning instruction with academic content standards: finding the link. Research \& Practice for Persons with Severe Disabilities, 31, 309-321. https://doi.org/10.1177/154079690603100404

Bryan, R. R., McCubbin, J.A., \& Van Der Mars, H. (2013). The ambiguous role of the paraeducator in the general physical education environment. Adapted Physical Activity Quarterly, 3o(2), 164-183. https://doi.org/10.1123/apaq.30.2.164

Calculator, S. (2009). Augmentative and alternative communication (AAC) and inclusive education for students with the most severe disabilities. International Journal of Inclusive Education, 13, 93-113. https://doi.org/10.1080/13603110701284656

Carter, N., Prater, M. A., Jackson, A., \& Marchant, M. (2009). Educators' perceptions of collaborative planning processes for students with disabilities. Preventing School Failure: Alternative Education for Children and Youth, 54(1), 60-70. https://doi.org/10.3200/PSFL.54.1.60-70

Causton, J., \& Tracy-Bronson, C. (2015). The educator's handbook for inclusive school practices. Baltimore, MD: Brookes.

Cook, L., \& Friend, M. (2010). The state of the art of collaboration on behalf of students with disabilities. Journal of Educational Psychological Consultation, 2O(1), 1-8. https://doi.org/10.1080/10474410903535.398

Corbin, J. M., \& Strauss, A. (1990). Grounded theory research: Procedures, canons, and evaluative criteria. Qualitative Sociology, 13(1), 3-21. https://doi.org/10.1007/BFo0988593

Creswell, J. (2013). Research design: Qualitative, quantitative, and mixed methods approaches. London: Sage.

Dymond, S. K., Renzaglia, A., Gilson, C. L., \& Slagor, M. T. (2007). Defining access to the general curriculum for high school students with significant cognitive disabilities. Research and Practice for Persons with Severe Disabilities, 32, 1-15. https://doi.org/10.1207/S15327035EX0903 2

Downing, J. E., Hanreddy, A., \& Peckham-Hardin, K. (2015). Teaching communication skills to students with severe disabilities (3rd ed.). Baltimore, MD: Paul H. Brooks.

Finnerty, M., Jackson, L., \& Ostergren, R. (2019). Adaptation in general education classroom for students with severe disabilities: Access, progress assessment and sustained use. Research and Practice for Persons with Severe Disabilities, 44(2), 87102. https://doi.org/10.1177/1540796919846424

Florian, L. (Ed.). (2014). The Sage Handbook of Special Education, (2nd ed.). London: Sage. https://doi.org/10.4135/9781446282236

Foulger, T.S. (2010). External conversations: An unexpected discovery about the critical friend in action research inquiries. Action Research, 8(2), 135-152. https://doi.org/ 10.1177/1476750309351354

Fullan, M. (2001). Leading in a culture of change. San Francisco: Jossey-Bass.

Galdas, P. (2017). Revisiting bias in qualitative research: Reflections on its relationship with funding and impact. International Journal of Qualitative Methods, 16, 1-2. https://doi.org/10.1177/1609406917748992

Grenier, M., \& Lieberman, L.J. (Eds). (2018). Physical education for students with moderate to severe disabilities. Champaign, IL: Human Kinetics.

Hamilton-Jones, B., \& Vail, C. (2013). Preparing special educators for collaboration in the classroom: Pre-service teachers' beliefs and perspectives. International Journal of Special Education, 28, 56-68. https://doi.org/eric.ed.gov/?id=EJ1034079

Ji, A., \& Meaney, K. (2015). Inclusion practices in elementary physical education: A socialcognitive perspective. International Journal of Disability, Development and Education, 62(2), 143-157. https://doi.org/10.1080/1034912X.2014.998176

Klavina, A., \& Rodionova, K. (2015). The effect of peer tutoring in physical education for middle school students with severe disabilities. European Journal of Adapted Physical Activity, 8(2), 3-17. https://doi.org/10.5507/euj.2015.005

Kurth, J. A., Ruppar, A. L., McQueston, J. A., McCabe, K. M., Johnston, R., \& Toews, S. G. (2019). Types of supplementary aids and services for students with significant support needs. The Journal of Special Education, 52(4), 208-218.

http://doi.org/10.1177/0022466918791156 
Kurth, J., Lyon, K., \& Shogren, K. (2015). Supporting students with severe disabilities in inclusive schools: a descriptive account from schools implementing inclusive practices. Research and Practice for Persons with Severe Disabilities, 40, 261-274. https://doi.org/10.1177/1540796915594160

Lincoln, Y. S., \& Guba, E. G. (1985). Naturalistic inquiry. Beverly Hills, CA: Sage.

McGrath, O., Crawford, S., \& O’Sullivan, D. (2019). 'It's a challenge': Post primary physical education teachers' experiences of and perspectives on inclusive practice with students with disabilities. European Journal of Adapted of Physical Activity, 12(1), 2. https://doi.org/10.5507/euj.2018.011

Nilsen, S. (2017). Special education and general education - coordinated or separated? A study of curriculum planning for pupils with special educational needs. International Journal of Inclusive Education, 21(2), 205-217. https://doi.org/10.1080/13603116.2016.1193.564

Olson, A, Leko, M., \& Roberts, C. (2016). Providing students with severe disabilities access to the general education curriculum. Research and Practice for Persons with Severe Disabilities, 41, 143-157. https://doi.org/10.1177/1540796916651975

Orelove, F., Sobsey, D., \& Gilles, D. (2017). Educating Students with Severe and Multiple Disabilities: A Collaborative Approach. Baltimore: Brookes.

Patton, M. Q. (2015). Qualitative Research and evaluative methods: Integrating Theory and Practice (4th ed). Thousand Oaks, CA: Sage Publications.

Pecora, J.K., Whittaker, J.K., Maluccio, A.N., \& Barth, R.P. (2012). The child welfare challenge: Policy, practice and research (3rd ed.). New Brunswick, NJ: Aldine Transaction. https://doi.org/10.4324/9781315131245

Pocock, T. \& Miyahara, M. (2018). Inclusion of students with disability in physical education: a qualitative meta-analysis. International Journal of Inclusive Education, 22(7), 751-766. https://doi.org/10.1080/13603116.2017.1412508

Richards, K. A., \& Hemphill, M.A. (2018). A practical guide to collaborative qualitative data analysis. Journal of Teaching in Physical Education, 37(2), 225-231. https://doi.org/10.1123/jtpe.2017-0084

Ryndak, D. L., Moore, M. A., Orlando, A., \& Delano, M. (2008). Access to the general curriculum: The mandate and role of context in research-based practice for students with extensive support needs. Research and Practice for Persons with Severe Disabilities, 34(1), 199-213. https://doi.org/10.2511/rpsd.33.4.199

Samalot-Rivera, A., \& Lieberman, L.J. (2017). Adapted Physical Educators current involvement in the IEP process. Palaestra, 31, 22-27. https://js.sagamorepub.com/palaestra/article/view/8588

Schatzman, L., \& Strauss, A. (1973). Field research. Englewood Cliffs, NJ: Prentice Hall.

Tant, M., \& Watelain, E. (2016). Forty years later, a systematic literature review on inclusion in physical education (1975-2015): A teacher perspective. Educational Research Review, 19, 1-17. https://doi.org/10.1016/j.edurev.2016.04.002

Timberlake, M. T. (2014). Weighing costs and benefits: Teacher interpretation and implementation of access to the general education curriculum. Research and Practice for Persons with Severe Disabilities, 39(2), 83-99. https://doi.org/ $10.1177 / 1540796914544547$

United Nations (2006). Convention on the rights of persons with disabilities. New York: NY: United Nations.

United Nations Educational, Scientific and Cultural Organization. (2015). "International Charter of Physical Education, Physical Activity and Sport." http://unesdoc.unesco.org/images/0023/002354/235409e.pdf

Waldron, N., \& McLeskey, J. (2010). Establishing a collaborative school culture through comprehensive school reform. Journal of Educational and Psychological Consultation, 20, 58-74. https://doi.org/10.1080/104744109035.35364

Whittemore, R., Chase, S., \& Mandle, C. (2001). Pearls, pith and provocation: Validity in qualitative research. Qualitative Health Research, 11(4), 522-537.

https://doi.org/10.1177/104973201129119299 
Wilhelmsen, T. \& Sorensen, M. (2017). Inclusion of children with disabilities in physical education: A systematic review of literature from 2009 to 2015. Adapted Physical Activity Quarterly, 34(3), 311-337. https://doi.org/10.1123/apaq.2016-0017

Zitomer, M., \& Goodwin, D. (2014). Gauging the quality of qualitative research in adapted physical activity. Adapted Physical Activity Quarterly, 31(3), 193-218. https://doi.org/ 10.1123/apaq.2013-0084 under the terms and conditions of the Creative Commons Attribution (CC BY) license (http://creativecommons.org/licenses/by/4.o/). 